Journal of Computer Science 3 (3): 180-185, 2007

ISSN 1549-3636

(C) 2007 Science Publications

\title{
A Study of the Contracting and Procurement Process for Cots Software Projects
}

\author{
${ }^{1}$ Mansoor A. Al A'ali, ${ }^{2}$ Seema A. Al Mahmood and ${ }^{3}$ Ala Al-Zobaidie \\ ${ }^{1}$ Department of Computer Science, College of Information Technology \\ University of Bahrain, PO Box 32038, Kingdom of Bahrain \\ ${ }^{2}$ Bahrain Telecommunication Company, Kingdom of Bahrain \\ ${ }^{3}$ School of Computing and Mathematical Sciences, The University of Greenwich, UK
}

\begin{abstract}
The subject of contracting and procurement in relation to COTS software projects has not been well studied. This study discusses issues related to contracting and procurement process in COTS (Commercial Of The Shelf) software acquisition projects. The research is based on the analysis of three case studies of major COTS projects in Bahrain. Based on the case studies analysis and the literature review, we present a solution in the form of a "contracting and procurement" guidelines to be adopted in the Contracting and Procurement Process of COTS software systems.
\end{abstract}

Key words: Software engineering, software requirements, cooperative work support

\section{INTRODUCTION}

The critical elements of software development projects and the agreements that underpin them is a major issue ${ }^{[1,2]}$. The starting point for a software development project is the definition of requirements, which is usually triggered by the need for a new business product or the implementation of new or upgraded business support systems, such as inventory management or e-procurement. Once the high-level business requirements have been agreed, they are expanded into a detailed specification, akin to architectural drawings and materials specifications for building a house

The importance of the relationship between customers and suppliers of goods and services has been recognized for many centuries ${ }^{[3,4]}$. The management of customer/supplier relationships encompasses all the activities associated with the flow of goods and services from suppliers to end users. A number of organizations may be involved in such supply chains and the relationships established between partner organizations play a vital role in the success of a particular supply chain. The characteristics of software supply chains across a range of development/procurement paradigms depend primarily on the nature of the relationship between software customers and software suppliers, with insights into the changing role of the customer. The procurement paradigms include: commercial offthe-shelf (COTS) products, component-based software engineering and software service engineering.
Companies have not taken advantage of the benefits reaped from having procurement professionals involved in purchasing software ${ }^{[5,6]}$. Benefits include objective supplier evaluation, fair bidding opportunities, negotiation experience and long-term software provider relationship management.

The purchasing process coordinates all the different players involved in the process to secure, implement and manage the contract. Purchasing takes on such a leadership position because of its expertise at negotiation and contract management ${ }^{[7]}$. Benefits of purchasing involvement in the software buy include cost savings resulting from successful negotiation. Purchasing professionals involved in the software buy have an understanding of terminology and components of the agreement. Software buyers should follow the best practices and know the type of software needed. A standard approach for the contracting process helps to reduce the time it takes to go through the contracting process. To manage the agreement, software buyers may use contract management software or a simple access database.

Contemporary software is increasingly developed using an agile development approach, yet the supplier is generally selected as a result of a waterfall-style competitive tendering and contracting process ${ }^{[8]}$. The procurement activity may be incompatible with an agile development of functionality and lead to sub-optimal outcomes. The interaction of the procurement and software development lifecycles and the potential causes of project or system failures must be explored.

Corresponding Author: Mansoor A. Al A'ali, Department of Computer Science, College of Information Technology, University of Bahrain, P.O. Box 32038, Kingdom of Bahrain 
Recently, researchers have begun investigating an emerging, technology-enabled innovation that involves the use of intelligent software agents in enterprise supply chains ${ }^{[9]}$. Software agents combine and integrate capabilities of several information technology classes in a novel manner that enables supply chain management and decision making in modes not supported previously by IT and not reported previously in the information systems literature. Indeed, federations and swarms of software agents today are moving the boundaries of computer-aided decision making more generally. Such moving boundaries highlight promising new opportunities for competitive advantage in business, in addition to novel theoretical insights. But they also call for shifting research thrusts in information systems. The stream of research is taking some first steps to address such issues by examining experimentally the capabilities, limitations and boundaries of agent technology for computer-based decision support and automation in the procurement domain ${ }^{[10]}$.

Procurement represents an area of particular potential for agent-based process innovation, as well as reflecting some of the greatest technological advances in terms of agents emerging from the laboratory ${ }^{[9]}$. Procurement is imbued with considerable ambiguity in its task environment, ambiguity that presents a fundamental limitation to IT-based automation of decision making and knowledge work. By investigating the comparative performance of human and software agents across varying levels of ambiguity in the procurement domain, the experimentation helps to elucidate some new boundaries of computer-based decision making quite broadly. The techniques should be thought of as aids to decision-making and not the substitutes for it. Numerous decision-making techniques have been proposed as effective methods of ranking software products for selection for use as components in large-scale systems. Many of these techniques have been developed and successfully applied in other arenas and have been either used directly or adapted to be applied to COTS product evaluation and selection.

Component-based software engineering is typically perceived as application development in which existing individual software components are assembled and integrated in order to make up the final product ${ }^{[11]}$. The main recent technological advances in this field therefore mainly focus on the integration step. This encompasses the syntactic and semantic mapping between components, the development of component wrappers and adapters and the validation of all pairwise component interactions. Additionally, prior to integration, components have to be located on a component market place, evaluated for their fitness for the purpose and selected according to non-functional requirements. These activities are typically referred to as component procurement. Component brokerage platforms provide the support for these early phases of component assembly and they are indispensable for strengthening the software component market. Although such platforms are good at the provision of components, they are not so good at their certification. A combination of two contrasting technologies, component brokerage at one end of the component technology spectrum is required. A built-in contract testing may alleviate the efforts involved in component certification.

Commercial off-the-shelf (COTS) software: "Commercial Off-the-shelf" (COTS) software have been widely used by many organizations as a means of developing Information Systems (IS) with lower risks, lower costs and shorter development schedule while increasing functionalities and the capabilities of the system. The management expectation is that COTS system components are easy to implement to work in different environments and to customize to the organization's local requirements. This is not entirely true in all situations. Project managers find that managing this type of software acquisition projects is a challenge and carries many risks. Project managers face many problems during the life cycle of the project, some of these problems may cause the project to fail, to increase the project costs significantly - unexpected costs and to not meet any special requirements. Investigating the problems that project managers face in managing software acquisition projects represents a substantial issue for study and research.

The move to COTS products caused fundamental changes in the way that organizations do business. This change can be described as "paradigm shift". The essence of the paradigm shift is that organizations will change from a producer to a consumer. In a producer case, developers create the components or implement the system. Therefore, the system will be viewed from every aspect because developers have control over all its features and functions. In a consumer case, the organization purchases a COTS product after viewing only the product's interfaces instead of defining unique interface specifications, consumers adopt standard interface specifications. The specifications will be selected as a result of market research. Instead of developing implementations, the consumer procures implementations that are based on standard interfaces. These implementations will be standard-based COTS products. The integration of the product is different and 
possibly more difficult, because the consumer has less insight into the product. In some cases, a vendor may not want its products to integrate with others.

The COTS process as presented by Morisio et $a l .{ }^{[12]}$ ) list the stages of the COTS software acquisition process as: Requirements Analysis, System Requirement Review, Package Identification Evaluation/Selection, Glueware and Integration Requirements, System Design Review, Non COTS Development (Glueware and Interfaces), Integration and Testing, Target System Installation and Acceptance Test, Discrepancy resolution and Sustaining Engineering.

With regard to IS procurement formalization, Heckman $^{[13]}$ studied the formalization of IT procurement function, his findings showed that most

companies have a formal defined supplier management process and assigned staff full-time to manage supplier relationship. Meyers and Oberndorf $\mathrm{f}^{[14]}$ emphasized that training is required in COTS products for the contractor team. In addition, Meyers and Oberndorf ${ }^{[14]}$ discussed the importance of the contract and defined the basic contract types used in software acquisition projects. Fixed-price contract provides a price that is not subject to any adjustment on the basis of the contractor's cost experience in performing the contract. Another type is "cost-reimbursement contract", this type promises payment to the contractor of allowable costs incurred during the contract process development which will be included in the contract itself. It establishes an estimate of the total cost for the purposes of obligation of funds and establishing a ceiling that the contractor may not exceed, except at its own risk, without prior approval or subsequent ratification of the contracting offices. The third type is "time and material contract", which promises an hourly rate for labor and a fixed price for materials owed to the contractor for the entire transaction described in the contract.

Another aspect discussed by Meyers and Oberndorf $^{[14]}$ when acquiring a system is the contracting strategies; he defined five basic strategies as follows:

1. Control strategy: The client specifies the system requirements, standards, profile and standardsbased implementations and conduct conformance qualifications. The vendor integrates the system.

2. Direct strategy: The client collects and specifies requirements, standards and a profile. The vendor conducts the conformance qualifications, selects the standards-based implementations and integrates the system.
3. Guide strategy: The client specifies requirements and set standards to be used. The vendor creates the standards profiles, conducts the conformance qualifications, selects the standards-based implementations and integrates the system.

4. Initiate strategy: The client specifies the requirements and vendor performs the rest.

5. Joint strategy: Both the client and the vendor share the decision-making responsibility through one or more integrated product teams.

They also mentioned the key difference among the five strategies is in how they spread the risks and responsibilities among various participants. Strategy 1 places a heavy burden on the acquirer with respect to both risk and responsibility, whereas strategy 4 shifts a large share of that burden to the contractor and strategy 5 shares the risk and responsibility more equitably.

Regarding the content of the contract, the four key aspects of contract documentation as defined by Meyers and Oberndorf ${ }^{[14]}$ are request for proposal (RFP), statements of work and instructions to vendor and evaluation factors.

Yardley ${ }^{[15]}$ described the supplier management process in three stages: pre-contract, invocation (signature) and during the contract. The pre-contract stage is the process of inviting IT suppliers or service providers to bid for work through mechanisms such as an Invitation to Tender (ITT) or a Request for Proposal (RFP). One of the key points discussed here that the information sent to suppliers should indicate the schedule for the selection process but it should not disclose any details about the selection process itself. In the invocation stage, the basis of the contract must be a singed agreement between both parties, in which the details are clearly defined. In this stage he focused on the importance that the individual who will negotiate the contract with supplier is not the same individual who will manage the project of which the contract forms a part., this is to avoid the strain that may happen on the relationship between the customer and supplier. The final stage is during the contract, which he pointed that once the contract is singed it should not be referred unless if there are problems with the supplier. In addition, he mentioned that one of the causes of IS project failure is not having a contract with the supplier which means that the project is based on informal understanding of work.

Case studies projects: We have selected for our research three major multi-million dollar COTS projects for analysis in terms of the Contracting and Procurements procedures and issues adopted. A summary of these three COTS projects is given below. 
Project 1: Human resources management systems: The Human Resources Management Systems HRMS project (P1) was initiated in September 2000 to replace the old HR system with authorized budget of $\$ 1.8 \mathrm{~m}$ and with the expectation of a project completion of 9 months. The project was divided into 2 phases: Phase 1 : Oracle HRMS Implementation (5 months) to cover the delivery of the core HRMS product i.e. HR, Payroll and Training modules and Phase 2: (4 months) to cover Employee Self-Service and HR intelligence. This solution was selected due to its superior functionality and best fit for the company HR requirements. Phase 1 of the project was completed twelve months behind schedule and due to major problems with the vendor the contract was terminated and the project was stopped at that stage. The project was restarted eight months after it was stopped and another vendor was selected to complete the project. The new vendor re-implemented Phase 1, upgraded the applications and completed phase 2 of the project. The system was launched in six months from the start date serving around 1176 users.

Project 2: Corporate financial systems (CFS): The CFS project (P2) was initiated in September 2000 with a budget of $\$ 8.5 \mathrm{~m}$ and with the expectation of a project completion in February 2002 (time frame of 18 months). A vendor was selected to implement SAP R/3 computer applications that replaced the old systems in areas of finance and logistics. Five SAP modules were implemented. The system was launched in January 2002 and the project was marked as a success with comparison to other major IS projects as it was implemented in time and under budget.

Project 3: Call centre automation (CCA): The CCA project (P3) was initiated in November 2002 with authorized budget of $\$ 2.7 \mathrm{~m}$ and with the expectation of a project completion in July 2003 (time frame of 9 months). Vendor D was selected to implement an integrated Interactive Voice Response System (IVR), a Call Routing System and Computer Telephony Integration (CTI) that replaced the old systems on the company Call Centres. The system was launched in November 2003 with a delay of 4 months.

\section{RESULTS AND DISCUSSION}

The major contribution for this study is the proposal of the listed set of Guidelines for the Contract and Procurement of major COTS software system as shown in Fig. 1.

When project P1 started up, there was a newly formulated Information Systems (IS) procurement group that was not available at the time of starting up projects P2 and P3. Although a job description was created specially for the procurement job, all the procurement staff were not from IS background and they did not report to IS management but to Finance management.

In the cases of $\mathrm{P} 1$ and $\mathrm{P} 2$, a procurement manager was assigned to handle the contract preparation and he was specialized in preparing IS contracts but did not have IS background. In case of project P3, a new procurement employee was assigned to participate in the contract preparation, she was new to the job, did not have experience in contract preparation and did not have IS background too.

IS procurement strategies: The three project managers agreed that there is no procurement strategy defined for software acquisition projects, but the most appropriate and applied strategy was "Control strategy".

Contract issues: In projects $\mathrm{P} 1$ and $\mathrm{P} 2$, there was a very detailed legal contract prepared and signed with the vendor; it was prepared by the procurement manager, but some contract parts related to hardware and software were developed jointly by IS managers, IS specialists and procurement manager. This was considered as a template to be used for future IS projects. Project P1 contract supported IS project manager to terminate the contract with the first vendor when major problems arose during the project.

1. Establish the IT procurement team: The first step in the contracting and procurement process is to form an IT Procurement Team. This team should consist of an experienced IT procurement manager, IT project manager and an IT technical project member. The vendor team should be part of this process at some stage. It is important that the procurement manager has an acceptable background in IT in order to assist in establishing a well defined contract with the vendor. Any organization should establish an IT procurement team with defined job descriptions that clarify the roles and responsibilities in participating in such a process. In addition, provide specialized training for procurement staff in COTS software acquisition contract preparation and hire new procurement staff with information systems qualifications. Further, for large projects, experienced procurement staff should be assigned the task of contract preparation and negotiation with the vendor.

2. Define IT procurement team reporting: Establish decision making hierarchy or procedure whereby IT procurement team should report and be part of IT organization in order to make decision making well studied a process and taken without being affected by decisions from other units.

3. Establish formal procurement strategies for software acquisitions.

4. Decide on the contracting strategies to use on software acquisition projects: The selection of the strategy type helps in dividing the responsibilities of the projects between the client 
and the vendor and will also have a direct impact on the content of the contract. The contracting strategies are: Control strategy, Directing strategy, Guiding strategy, Initiating strategy \& Joint strategy

5. Decide who is responsible for creating the IT procurement strategies.

6. A formal legal contract must be officially signed by vendor and organization before any project work starts.

7. Decide on the negotiation process with the vendor.

8. Decide on the parts that should be included in the contract.

* RFP: including functional and non-functional requirements

* $\quad$ Statement of work (SOW)

* Instructions to vendors

* Evaluation factors

* CVs of vendor teams assigned to the project - this is required to ensure high quality team skills and qualifications

* Defined project cost covering the project scope and a cost plan for out of scope requirements

* Terms and conditions

* Non-disclosure agreement (NDA)

9. Decide on any other expectations other than those included in the contract.

10. Decide on the contract type. This is important to identify the possible effects of the contract type on the project and what problems it could create later.

* $\quad$ Fixed price contract: should be used when the project scope is clear and the requirements are well defined and the probability of unplanned requirements is not considered.

* Cost reimbursement contract (cost plus fixed fee, cost plus incentive fee): this type of contract should be used in cases where a well defined requirements are defined but with a possibility of introducing additional requirements to the original scope.

* Time and material contract: this type of contract should be used in cases where the requirements are not clearly defined and the scope could change.

Fig. 1: Proposed guidelines for the contract and procurement of major COTS software system

In case of project $\mathrm{P} 3$, no final contract was prepared or signed with the vendor; instead, only a Letter of Intent (LOI) was signed with the vendor.

Projects P1 and P2 contracts covered: Technical fit, functional fit and commercial fit which met almost all the project expectations; they covered the following areas in details:

* Request for Proposal (RFP)

* Statement of work (SOW)

* Instructions to vendor

* Terms and conditions

* Cost schedule

* Project plan

* Non-Disclosure Agreement (NDA).

* Vendor responses to RFP

* All correspondences with the vendor - from RFP till final agreement. This was important for future references and to keep track of clarifications of some critical issues.
The contract type for projects P1 and P3 was a "Fixed Price Contract" which provided a price that is not subject to any adjustment on the basis of the vendor's cost experience in performing the contract. However, the project manager of P1, emphasized that this type of contract was good because it put a time frame and budget limits for the vendor but at the same time needs a well defined project scope and requirements. Moreover, additional requirements that were added later on the project incurred more cost on the project.

In project $\mathrm{P} 3$ case, due to lack of a finalized contract, the company lost BD 660,000, due to cancellation of one of the requirements. The vendor had to refund the amount of this requirement which was $\mathrm{BD}$ 670,000 , but they refunded BD 10, 000 only!

Project P2 contract type was "Time and Material with Ceiling Contract". Project P2 project manager said regarding this issue "The contract type overcame the problems of fixed price contract, as it was difficult to get an accurate project scope and requirements at the beginning of the project. This type made the project more flexible in accommodating new or changes in business requirements and in time too. It also made us better control the cost of the project."

Contract negotiation process: Regarding the contract negotiation process with the vendor, projects $\mathrm{P} 1$ and $\mathrm{P} 2$ described the negotiation process to be long and consists of the following steps:

* Prepared first draft of the contract

* Discussed each clause of the contract in detail with the selected vendor

* Updated the contract and continued negotiating till a final contract was prepared and signed.

Project P3 negotiation process was done late in the project and it was very weak because the vendor knew earlier the budget allocated by the company to the project so they were insisting to charge high costs. Another factor affected the negotiation process negatively was the fact that the procurement staff assigned to the job was new and inexperienced.

IS procurement staff: The findings support Heckman $^{[13]}$ study in that the company had a formal IS Procurement Strategies: In line with Meyers and Oberndorf ${ }^{[14]}$, the strategy used in all three projects was the "control" contracting strategy; using this strategy 
placed a heavy burden on IS project team in terms of risk and responsibility.

\section{REFERENCES}

1. Pressman, R., 2000. Software Engineering. UK, McGraw-ill Publishing Company.

2. Murphy, R., 2004. Creating the contract [software sourcing]. Supply Management, 30-1, UK.

3. Brereton, P., 2004. The software customer/supplier relationship. Source: Communications of the ACM, 47: 77-81.

4. Lander, M., 2004. Trust-building mechanisms utilized in outsourced IS development projects: A case study. The J. Inform. Manag., 41: 509-528.

5. Atkinson, W., 2003. Buying software: Why you need to be involved. Purchasing, 132: 22-3.

6. Thoren, C., 2004. The procurement of usable and accessible software. Universal Access in the Information Society, 3: 102-6, Springer-Verlag, Germany.

7. Avery, S., 2003. Sourcing software? An expert offers how-to tips. Purchasing, 132: 26, 28-9.

8. Jamieson, D., K. Vinsen and G. Callender, 2005. Agile procurement to support agile software development. 3rd IEEE Intl. Conf. Industrial Informatics (INDIN) (IEEE Cat. No. 05EX1057), pp: $419-24$.
9. Nissen, M.E., Monterey and K. Sengupta, 2006. Incorporating software agents into supply chains: experimental investigation with a procurement task. MIS Quarterly, 30: 145-66.

10. Moynihan, G.P., P. Saxena and D.J. Fonseca, 2006. Development of a decision support system for procurement operations. Intl. J. Logis. Syst. Manag., 2: 1-18.

11. Gross, H.-G., M. Melideo and A. Sillitti, 2005. Self-certification and trust in component procurement. Sci. Computer Program., 56: 141-56.

12. Maurizio, M., C.B. Seaman, V.R. Basili, A.T. Parra, S.E. Kraft and S.E. Condon, 2002. COTSbased software development: Processes and open issues. The J. Systems and Software, 61: 189-199.

13. Heckman, R., 1999. Organizing and managing supplier relationships in information technology procurement. Intl. J. Information Management, 19: 141-155.

14. Meyers, B. and P. Oberndorf, 2001. Managing software acquisition: Open systems and COTS products, USA, Addison Wesley.

15. Yardley, D., 2002. Successful IT Project Delivery: Learning the Lessons of Project Failure, UK, Addison Wesley. 